\title{
Factors that influence a mobilized HSC product
}

\author{
Susan K. Nilsson ${ }^{1,2}$ (1)
}

Received: 16 November 2016 / Accepted: 13 December 2016 / Published online: 24 December 2016

(c) The Japanese Society of Hematology 2016

\section{Dear Editor,}

The presence of transplantable circulating peripheral blood (PB) hematopoietic stem cells (HSC) was first recognized in the 1960s [1], around the same time as the first described use of therapeutic apheresis [2], which is required to make PB HSC transplantation feasible. However, it was not until two decades later, after the discovery of granulocyte colony stimulating factor (G-CSF) [3], its isolation [4, 5] and subsequent demonstration of its ability to increase the concentration of HSC in the PB through a process termed mobilization [6], that mobilized PB HSC became a routine source HSC for transplantation (reviewed in [7]). Nevertheless, G-CSF based mobilization is not without its drawbacks, proving to be ineffective in some patients and causing a variety of shortterm side effects in others, driving efforts to develop more improved mobilization strategies (reviewed in [7]).

An improved understanding of how HSC are regulated and retained within the BM stem cell niche (reviewed in [8]) has enabled development of better HSC mobilization strategies. For example, the identification of the key role for the SDF-1:CXCR4 interaction in HSC function [9] has led to the successful implementation of the small molecule CXCR4 antagonist AMD3100 (plerixafor) in modern HSC mobilization regimes. Furthermore, several new agents are currently in development as faster, safer and more effective alternatives to current standards. Nevertheless, it is recognized that several factors can influence HSC mobilization

Susan K. Nilsson

susie.nilsson@csiro.au

1 CSIRO Manufacturing, Bag 10, Clayton South, VIC 3169, Australia

2 ARMI, Monash University, Clayton, VIC 3800, Australia and the subsequent mobilized product, which can ultimately have profound downstream effects on transplant outcomes.

In this issue, four review articles will cover various factors that influence a mobilized product used in HSC transplant. Winkler et al. highlight the various cellular components of the BM niche including neutrophils, endothelial cells, mesenchymal stromal cells, osteoblasts, osteoclasts and sympathetic neurons and the role they play, either directly or indirectly, on HSC mobilization [10]. Bendall summarizes the role of the extracellular molecules within the niche that facilitate HSC mobilization, with particular emphasis on sphingosine 1 phosphate (S1P), complement cascade and the neurotransmitters [11]. Le Texeira et al. review the potential of regulatory T-cells $\left(T_{\text {reg }}\right)$ for improving allogeneic HSC transplantation [12] and Domingues et al. provide an update on the latest HSC mobilization agents currently in development and their potential impact in clinical transplantation [13].

A complete understanding of all factors that influence HSC mobilization is critical for development of an "optimal" mobilized blood product. Such an optimal mobilized product should not only enable rapid and long-term HSC engraftment, but should also provide accompanying benefits such as reduced transplant associated costs, minimized donor side effects, reducing relapse rates when used in the treatment of disease, as well as balancing the effects of graft vs leukaemia and graft vs host effects in allogeneic transplants. With these considerations in mind, it is anticipated that the development of novel HSC mobilization agents, as well as the "optimization" of a transplant product will continue in the future.

The guest editor would like to thank all review authors for their contributions, Dr. Kitamura for the invitation to submit this Progress in Hematology and the Journal Office of International Journal of Hematology for their editorial work. 


\section{References}

1. Goodman JW, Hodgson GS. Evidence for stem cells in the peripheral blood of mice. Blood. 1962;19:702-14.

2. Schwab PJ, Fahey JL. Treatment of Waldenstroms macroglobulinemia by plasmapheresis. New Engl J Med. 1960;263:574-9.

3. Burgess AW, Metcalf D. The nature and action of granulocytemacrophage colony stimulating factors. Blood. 1980;56:947-58.

4. Nicola NA, Metcalf D, Matsumoto M, Johnson GR. Purification of a factor inducing differentiation in murine myelomonocytic leukemia-cells-identification as granulocyte colony-stimulating factor. J Biol Chem. 1983;258:9017-23.

5. Welte K, Platzer E, Lu L, Gabrilove JL, Levi E, Mertelsmann $\mathrm{R}$, et al. Purification and biochemical-characterization of human pluripotent hematopoietic colony-stimulating factor. P Natl Acad Sci USA. 1985;82:1526-30.

6. Duhrsen U, Villeval JL, Boyd J, Kannourakis G, Morstyn G, Metcalf D. Effects of recombinant human granulocyte colony stimulating factor on hematopoietic progenitor cells in cancerpatients. Blood. 1988;72:2074-81.
7. Bendall LJ, Bradstock KF. G-CSF: from granulopoietic stimulant to bone marrow stem cell mobilizing agent. Cytokine Growth Factor Rev. 2014;25:355-67.

8. Morrison SJ, Scadden DT. The bone marrow niche for haematopoietic stem cells. Nature. 2014;505:327-34.

9. Kucia M, Jankowski K, Reca R, Wysoczynski M, Bandura L, Allendorf DJ, et al. CXCR4-SDF-1 signalling, locomotion, chemotaxis and adhesion. J Mol Histol. 2004;35:233-45.

10. Tay J, Levesque JP, Winkler IG. Cellular players of hematopoietic stem cell mobilization in the bone marrow niche. Int J Haematol. 2017. doi:10.1007/s12185-016-2162-4

11. Bendall L. Extracellular molecules in hematopoietic stem cell mobilisation. Int $\mathrm{J}$ Haematol. 2017. doi:10.1007/ s12185-016-2123-y

12. Le Texier L, Lineburg KE, MacDonald PA. Harnessing bone marrow resident regulatory $\mathrm{T}$ cells to improve allogeneic stem cell transplant outcomes. Int J Haematol. 2017. doi:10.1007/ s12185-016-2161-5

13. Domingues MJ, Nilsson SK, Cao B. New agents in HSC mobilization. Int J Haematol. 2017. doi:10.1007/s12185-016-2156-2 